\title{
Intracardiac electrode detection of early ischaemia in
}

\section{$\operatorname{man}$}

\author{
R M DONALDSON, P TAGGART, H SWANTON, K FOX, D NOBLE, A F RICKARDS \\ From the National Heart Hospital; the Middlesex Hospital, London; and University Laboratory of Physiology, \\ Oxford
}

SUMMARY We have evaluated an intracardiac technique for the study of the electrophysiological patterns of early or subendocardial ischaemia in man. Simultaneous recordings of the paced endocardial evoked response and monophasic action potentials were obtained during pacing stress testing in 10 patients with reversible myocardial ischaemia. Early patterns of change occurred in both these recordings in response to regional ischaemia. Abnormal rate corrected shortening of the local repolarisation time in the paced endocardial evoked response from the left ventricular ischaemic zone diverging from control non-ischaemic values by a mean of $10.6 \%$ was paralleled by decreases in the simultaneous paced monophasic action potentials duration. A differential delay in the local activation time and conduction was also documented by the paced endocardial evoked response and monophasic action potential electrodes. Non-ischaemic control zones showed no changes in the pattern of activation and repolarisation. Disparate repolarisation times and asynchronous activation within the myocardium were thus consistently demonstrated during regional ischaemia. These changes in the endocardial paced evoked response and monophasic action potentials always preceded the appearance and regression of the clinical ischaemia.

Intracavitary recordings may thus provide earlier and more sensitive detection of regional ischaemia during cardiac catheterisation or coronary artery surgery. The study of the patterns of activation and response could permit the assessment of interventions on the early electrical changes of ischaemia, and may bridge the gap between in vitro studies and the electrophysiological studies performed upon the intact heart.

The acquisition of electrophysiological data during early ischaemia in the human heart is limited by the recording techniques available at present. Because the initial electrical changes are confined to a small region of the endocardium, 12 their manifestations in the electrocardiogram are usually absent or minor and delayed. ${ }^{34}$ Early ionic and electrical changes resulting from ischaemia are involved in the genesis of malignant ventricular arrhythmias 25 and abnormalities of myocardial contractility, ${ }^{3}$ and an appreciation of these changes is thus important.

We have recently reported the use of intracavitary electrode recordings of the paced evoked response and monophasic action potentials as indices of early electrophysiological changes produced by regional myocardial ischaemia in open chest dogs. ${ }^{6}$ In this study we have evaluated the possibility of applying

Supported by grants from the British Heart Foundation.

Accepted for publication 24 May 1983 these endocardial recordings to obtain electrophysiological data during early regional myocardial ischaemia in man.

\section{Patients and methods}

Intracavitary recordings were obtained in 10 patients (mean age 45.8 years) with localised coronary artery disease and ischaemia documented non-invasively and angiographically. These patients were selected on the basis of (1) normal resting electrocardiograms, (2) reproducible electrocardiographic evidence of ischaemia on treadmill exercise testing, (3) localised, reversible uptake defects on exercise and reperfusion imaging with thallium 201, (4) haemodynamically significant $(>75 \%)$ single vessel coronary artery disease documented angiographically, and (5) episodes of angina elicited by ventricular pacing during cardiac catheterisation, accompanied by an ischaemic elec- 
trocardiographic response. (ST depression of more than $1.5 \mathrm{~mm}$ ). Two of the patients developed additional $T$ wave inversion on the electrocardiographic recording during angina.

These patients were undergoing investigation of disabling angina and had reproducible evidence of myocardial ischaemia elicited by treadmill exercise testing. All cases developed exercise-induced ST segment abnormalities on the electrocardiogram before or at the onset of angina, which were documented using a modified 12 lead recording system. Three of these 10 patients had a strongly positive electrocardiographic response; five had moderately positive ischaemic responses and the two remaining patients had a mildly positive electrocardiographic abnormality. ${ }^{7}$

Information regarding perfusion at cellular level was obtained from exercise and redistribution thallium-201 myocardial perfusion imaging. Thallium-201 was injected intravenously $(1.5 \mathrm{mCi})$ at the onset of treadmill exercise limitation by angina pectoris; postinjection and delayed myocardial scintigrams were then obtained in the four standard views. A perfusion defect seen in the initial postinjection scan which concentrated activity late (so that the decreased tracer concentration was no longer visible three to four hours after injection) was considered to represent severe, reversible ischaemia. ${ }^{8}$ The uptake defect areas correlated well with the anatomical abnormalities visualised later at coronary arteriography (Table). The eight patients with septal uptake defects had corresponding lesions in the left anterior descending coronary artery. A ninth patient had a reversible defect in the posterolateral left ventricular wall and significant stenosis of both the main circumflex and its obtuse marginal branch. The remaining patient had an inferoapical uptake defect related to critical stenosis of a large dominant right coronary artery.

All medications except nitrates were discontinued 48 hours before the cardiac catheterisation procedure which included routine left ventriculography and coronary arteriography. Most of the patients were sedated with diazepam; all gave informed consent to the study.

The pacing stress test and the intracavitary recordings were obtained after the angiographic study had been completed.

A silicone rubber cardiac catheter incorporating three electrodes has been devised which permits the simultaneous recordings of the paced endocardial evoked response and monophasic action potentials from the human heart. This catheter was manipulated into either ventricle using at times the long sheath technique; a flexible guide wire in its central core facilitated positioning of the catheter (Fig. 1).

\section{RECORDING OF PACED ENDOCARDIAL EVOKED RESPONSE}

The method of sensing and recording the paced endocardial evoked response has been described in detail by us. ${ }^{\text {T }}$ The technique was a conventional unipolar pacing electrode which delivers a pacing stimulus of approximately $2.5 \mathrm{~mA}$ for $0.5 \mathrm{~ms}$ to the

*Siemens Elema AB, Sweden, size 8 French.

Table Changes in repolarisation, activation, and conduction times (ms) during clinical ischaemia derived from recordings of paced "control" non-ischaemic zones (NIZ)

\begin{tabular}{|c|c|c|c|c|c|c|c|}
\hline \multirow[t]{2}{*}{ Case No. } & \multirow{2}{*}{$\begin{array}{l}\text { MPI } \\
\text { Uptake defect }\end{array}$} & \multirow{2}{*}{$\begin{array}{l}\text { Diseased } \\
\text { coromary }\end{array}$} & \multirow{2}{*}{$\begin{array}{l}\text { ECG } \\
\text { changes } \\
\text { during } \\
\text { angina }\end{array}$} & \multirow{2}{*}{$\begin{array}{l}\text { Max. } \\
\text { heart } \\
\text { rate }\end{array}$} & \multirow{2}{*}{$\underset{(m s)}{C L}$} & \multicolumn{2}{|c|}{ Catheter position } \\
\hline & & & & & & RVNIZ & LVIZ \\
\hline $\begin{array}{r}1 \\
2 \\
3 \\
4 \\
5 \\
6 \\
7 \\
8 \\
9 \\
10\end{array}$ & $\begin{array}{l}\text { Septal } \\
\text { Septal } \\
\text { Septal } \\
\text { Septal } \\
\text { Septal } \\
\text { Septal } \\
\text { Posterolateral } \\
\text { Inferoapical } \\
\text { Septal } \\
\text { Anterior septal, } \\
\text { apical }\end{array}$ & $\begin{array}{l}\text { LAD } \\
\text { LAD Diag } \\
\text { LAD } \\
\text { LAD } \\
\text { LAD } \\
\text { LAD } \\
\text { LCx OM } \\
\text { RCA (Dom) } \\
\text { LAD } \\
\text { LAD }\end{array}$ & $\begin{array}{l}\text { ST } \\
\text { ST } \\
\text { ST } \\
\text { ST-T } \\
\text { ST } \\
\text { ST } \\
\text { ST } \\
\text { ST-T } \\
\text { ST } \\
\text { ST }\end{array}$ & $\begin{array}{l}110 \\
120 \\
140 \\
130 \\
100 \\
110 \\
100 \\
110 \\
120 \\
120\end{array}$ & $\begin{array}{l}545 \\
500 \\
430 \\
460 \\
600 \\
545 \\
600 \\
545 \\
500 \\
500\end{array}$ & $\begin{array}{l}\text { Base } \\
\text { Inf. basal } \\
\text { Inf. basal } \\
\text { Inf. basal } \\
\text { Inf. basal } \\
\text { Inf. basal } \\
\text { Ant. wall } \\
\text { Outflow tract } \\
\text { Inf. basal } \\
\text { Inf. basal }\end{array}$ & $\begin{array}{l}\text { Septal } \\
\text { Apex } \\
\text { Septal } \\
\text { Septal } \\
\text { Septal } \\
\text { Septal } \\
\text { Lateral wall } \\
\text { Inferior wall } \\
\text { Apex } \\
\text { Apex }\end{array}$ \\
\hline
\end{tabular}

\section{Mean \pm SD (ms)}

MPI, thallium 201 myocardial perfusion imaging; LAD, left anterior descending; LCx, circumflex; Diag, diagonal; OM, obtuse marginal artery; right coronary artery; ST, ST segment depression; ST-T, additional T wave inversion; CL, cycle length 


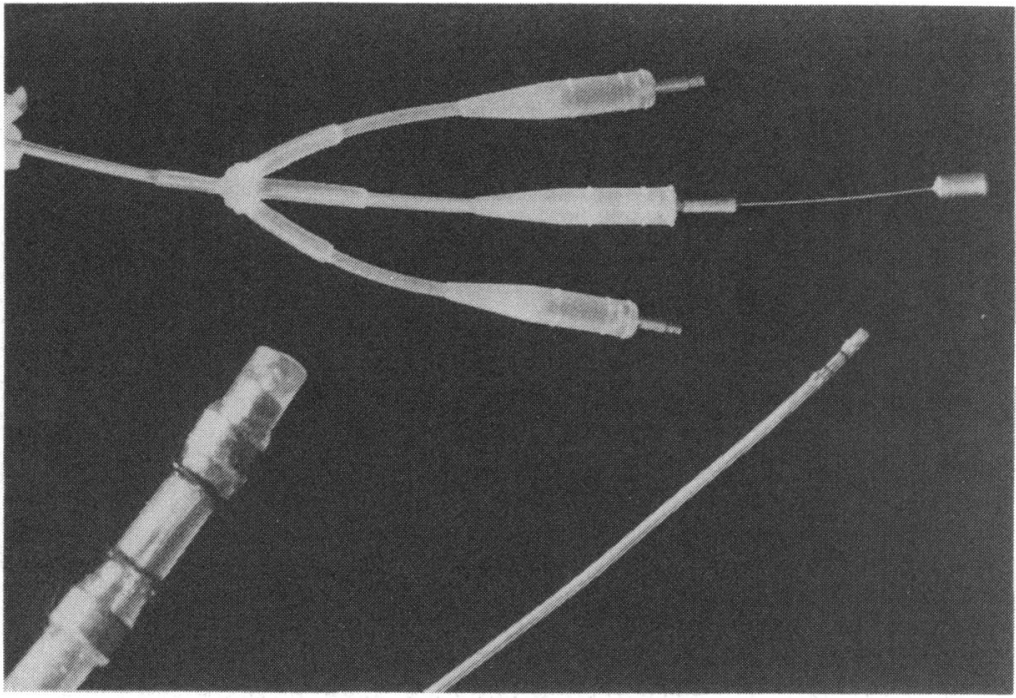

Fig. 1 Catheter used for the intracavitary recordings.

ventricular endocardium, care being taken to ensure that only the cathodal current is applied. This electrode is situated approximately $8 \mathrm{~mm}$ from the catheter tip, incorporated into the catheter wall. The paced endocardial evoked response is seen as a negative $Q R S$ wave reaching a nadir in approximately $\mathbf{4 0} \mathrm{ms}$ after the pacing pulse; this is followed by a clearly defined positive $T$ wave (Fig. 2). By using the same electrode for pacing and sensing, the system can record the local repolarisation after a controlled (paced) depolarisation. The incorporation of a peak detector with an adjustable sensing window into the pacemaker permits measurement of the interval between the applied stimulus and the peak of the evoked T wave automatically on a beat to beat basis. The stimulus to peak $T$ wave interval at each paced rate was taken as the average of 30 consecutive cycles after subtracting the 100 ms imposed by the detection system (Fig. 2). The distance between the pacing stimulus and the nadir of the negative QRS was deemed to represent activation time, while that between the stimulus and peak of the $T$ wave provides a measurement of the local repolarisation time, which is normally independent of pacing site and decreases during rapid pacing by approximately $1 \mathrm{~ms} /$ beat increment in rate.

\section{RECORDINGS OF MONOPHASIC ACTION POTENTIALS}

Extracellular potential changes were derived from recordings of monophasic action potentials. ${ }^{10}$ These

\begin{tabular}{|c|c|c|c|c|c|c|c|}
\hline \multicolumn{4}{|c|}{ epolarisation time } & \multirow{2}{*}{\multicolumn{2}{|c|}{$\begin{array}{l}\text { Activation time } \\
\operatorname{PER}(S t-Q R S)\end{array}$}} & \multirow{2}{*}{\multicolumn{2}{|c|}{$\begin{array}{l}\text { Conduction time } \\
M A P(S t \text {-upstroke })\end{array}$}} \\
\hline \multicolumn{2}{|c|}{$E R(S t-T)$} & \multicolumn{2}{|c|}{$\operatorname{MAP}\left(D_{90 \%}\right)$} & & & & \\
\hline ontrol & Ischaemic rome & Control & Ischaemic zone & Control & Ischaemic sone & Control & Ischaemic zone \\
\hline $\begin{array}{l}50 \\
30 \\
35 \\
50 \\
56 \\
10 \\
30 \\
78 \\
78 \\
35\end{array}$ & $\begin{array}{l}230 \\
260 \\
205 \\
222 \\
250 \\
215 \\
250 \\
210 \\
240 \\
250\end{array}$ & $\begin{array}{l}245 \\
265 \\
245 \\
235 \\
255 \\
240 \\
268 \\
252 \\
268 \\
280\end{array}$ & $\begin{array}{l}225 \\
245 \\
215 \\
207 \\
240 \\
220 \\
235 \\
225 \\
230 \\
250\end{array}$ & $\begin{array}{l}40 \\
38 \\
20 \\
55 \\
40 \\
35 \\
45 \\
36 \\
42 \\
35\end{array}$ & $\begin{array}{l}42 \\
42 \\
25 \\
60^{\star} \\
45 \\
38 \\
50^{\star} \\
40 \\
42 \\
40\end{array}$ & $\begin{array}{l}25 \\
30 \\
30 \\
22 \\
22 \\
20 \\
20 \\
30 \\
25 \\
35\end{array}$ & $\begin{array}{l}30 \\
34 \\
35 \\
38 \\
26 \\
25 \\
25 \\
32 \\
50 \\
45\end{array}$ \\
\hline $61 \cdot 2 \pm 17$ & $233 \cdot 2 \pm 18 \cdot 4$ & $255 \cdot 5 \pm 14$ & $229.2 \pm 12.8$ & $38 \cdot 6 \pm 8 \cdot 4$ & $42.4 \pm 8.42$ & $25.9 \pm 4.85$ & $34 \pm 8$ \\
\hline
\end{tabular}

t, stimulus; T, peak of the evoked T wave; QRS, peak of evoked QRS (negative deflection); $D_{90 \%}, 90 \%$ repolarisation time.

These figures are only approximate, as the fractionated electrograms of ischaemia did not enable the accurate quantification of the activation time. 


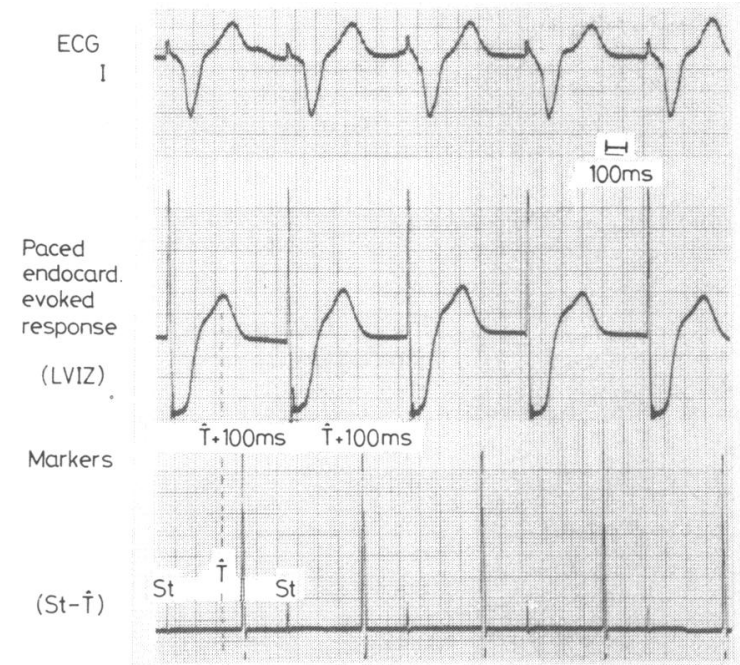

Fig. 2 The paced endocardial evoked response is seen as a negative $Q R S$ reaching a maximum amplitude approximately 40 ms after the pacing stimulus $(S t)$. The peak detector has an adjustable sensing window; this detector generates a marker pulse $100 \mathrm{~ms}$ after detection of the peak of the evoked $T$ wave $(T)$. This marker is recorded together with St, and the St-T interval measured automatically on a beat to beat basis by the pacing system. The St-T time is corrected by subtracting the $100 \mathrm{~ms}$ imposed by the pacing system. Paced cycle length $(C L), 600 \mathrm{~ms}$.

were obtained using a small $\left(0.3 \mathrm{~mm}^{2}\right)$ non-polarising carbon electrode placed in contact with the ventricular endocardium and referred to a local indifferent electrode. The distal monophasic action potential electrode located at the tip of the catheter is buffed off so that it was just recessed within the catheter tip; the indifferent electrode was brought out through a side hole drilled in the catheter $3 \mathrm{~mm}$ from the tip, flush with the wall. When the tip of the catheter impinges on the ventricular endocardium, monophasic action potentials of 20 to $40 \mathrm{mV}$ amplitude can be recorded (Fig. 3). No suction is used for these monophasic action potential recordings. Stable recordings for up to 15 minutes have been obtained from the same site, provided a good contact was maintained. The monophasic action potential signals were preamplified with a high impedance purpose built DC amplifier (Watco Limited).

The criteria for accepting the paced monophasic action potential recordings were the uniformity of the shape in 30 or more consecutive beats, their resemblance to the accepted configuration for transmembrane action potentials, a smooth repolarisation course, and a horizontal baseline (Fig. 3). Duration of monophasic action potentials was measured at $90 \%$ repolarisation time (Fig. 3). ${ }^{10}$ Changes in the interval between the pacing stimulus and the onset of mono-

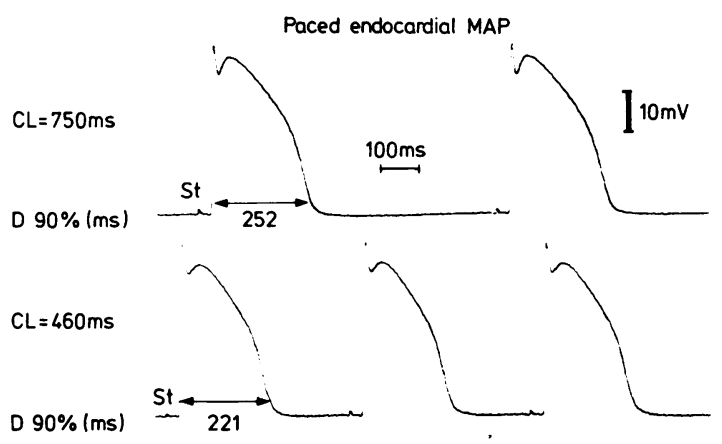

Fig. 3 Paced monophasic action potential (MAP) recordings from the lefi ventricular endocardium at cycle length $(C L)$ of 750 and $460 \mathrm{~ms}$. The $90 \%$ repolarisation time $\left(D_{90 \%}\right)$ is shown. St $=$ pacing stimulus.

phasic action potential upstroke were considered to represent changes in local conduction time.

\section{PROCEDURE}

One catheter containing both the paced endocardial evoked response and monophasic action potential recording elements was positioned under biplane fluoroscopic control in the potentially ischaemic zone in the left ventricle and the other in a "normal" zone of the right heart not affected by myocardial ischaemia. The normal non-ischaemic zone was located in the apex of the right ventricle in all but two cases. The intracardiac electrograms from the nonischaemic zone and from the potentially ischaemic zones were recorded alternately at paper speeds of 100 and 200 (or 250 ) $\mathrm{mm} / \mathrm{s}$ along with three selected electrocardiographic leads and the electronic peak detector using either an 8 channel ink-jet recorder (Siemens-Elema Mingograph 82) or an 8 channel heatsensitive recorder (Devices Instruments Limited model M19). The heart was stressed by ventricular pacing at progressively faster rates starting at 80 beats a minute and increasing the rate by 10 beats a minute every two minutes till the onset of angina or electrocardiographic evidence of ischaemia (Fig. 4) up to a maximal rate of 140 beats a minute. Either ventricle could be paced at any time (Fig. 4); sequential pacing periods of 60 seconds in each ventricle were used throughout the study. The unpaced scalar electrocardiogram was inscribed for 10 seconds before each increment in the paced rate.

Recordings of the paced endocardial evoked response and monophasic action potential from both the ischaemic and non-ischaemic zones were obtained sequentially throughout the pacing stress test till the onset of angina or electrocardiographic evidence of myocardial ischaemia; measurements were then made 


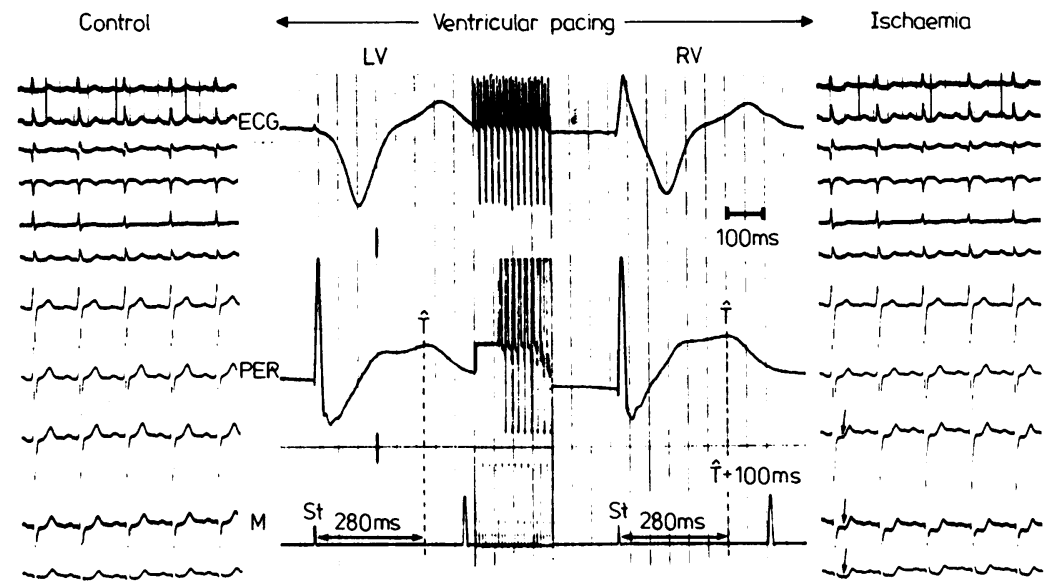

Fig. 4 After obtaining the control electrocardiogram (left panel, showing from above downwards, the six standard leads and the precordial leads $V_{2}$ to $V_{6}$ ), recordings of the paced endocardial evoked response (PER) were registered sequentially from both ventricles (middle panel) throughout the pacing stress test till the onset of angina or electrocardiographic evidence of ischaemia (right panel, arrows). Abbreviations as in Fig. 2.

alternately from both control and ischaemic areas of the heart for over 30 beats and used as end points for each individual study (Table). Sublingual or intravenous nitrates were administered immediately after the recordings at ischaemia had been completed. After angina stopped and during the regression of the electrocardiographic changes, further intracavitary measurements were obtained from the left ventricular catheter at paced rates matched to those used for the ischaemic recordings, to establish the rate of reversibility of the ischaemic electrical changes.

After a 10 minute recovery, four patients underwent an additional pacing stress test starting at the predetermined pacing rate threshold for angina, with almost continuous recordings of the paced endocardial evoked response and monophasic action potential from the ischaemic zone only until the onset of clinical ischaemia documented by the electrocardiogram during the switch off periods of pacing.

\section{DATA ANALYSIS}

The data obtained by both paced endocardial evoked response and monophasic action potential recordings from the non-ischaemic and ischaemic sites at identical paced cycle lengths were compared using paired $t$ statistics.

\section{Results}

Changes (expressed as a percentage of the initial values) in the duration of the local repolarisation as evaluated by the paced endocardial evoked response from the right ventricular non-ischaemic zone and from the left ventricular ischaemic zone during the pacing stress test are shown in Fig. 5, which also superimposes the expected rate-dependent range of the paced endocardial evoked response as documented from both ventricles in seven normal subjects. The rate adjusted paced endocardial evoked response from the non-ischaemic zone remained within the normal range throughout the study and these values from the right ventricle during clinical ischaemia (mean 261.2 $\pm 17 \mathrm{~ms}$ ) were used as "control" measurements (Table). The mean duration of the paced endocardial evoked response recorded at angina from the left ventricular ischaemic zone (mean $233.2 \pm 18.4 \mathrm{~ms})$ differed significantly $(p<0.001)$ from these control measurements (Table). The readings from the two areas of the heart diverged for a time before the onset of angina, and local repolarisation in the left ventricular ischaemic zone was shortened dur-

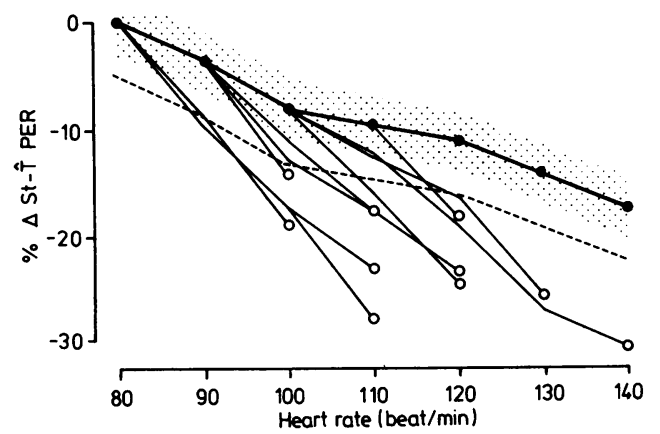

Fig. 5 Centile changes in the paced endocardial evoked response $(P E R)$ during ventricular pacing. The paced endocardial evoked response from the non-ischaemic zone (black circles) remained within the rate dependent range (dotted area) obtained from seven patients with normal coronary arteriograms and left ventriculograms. The dashed line represents the $95 \%$ confidence limits $(S D \times 2)$ that is $( \pm 5 \%)$ of control. The paced endocardial evoked response from the ischaemic zone diverged from control earlier and at lower rates than those required to produce clinical ischaemia (white circles). 


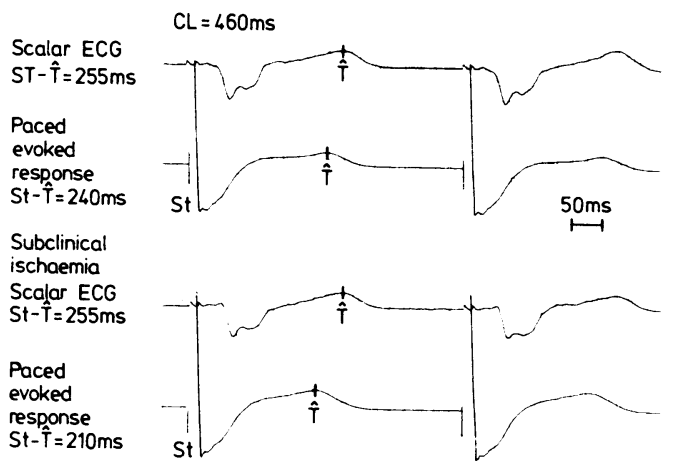

Fig. 6 Subclinical ischaemia. Recordings of the paced endocardial evoked response from the left ventricular ischaemic zone (case 3). The top tracings were obtained 15 seconds after increasing the paced rate to $130 \mathrm{bpm}$ (cycle length, $460 \mathrm{~ms}$ ). The lower recordings obtained 90 seconds later document a $30 \mathrm{~ms}$ $(-12.5 \%)$ decrease in the local repolarisation time corresponding to "subclinical" ischaemia. Myocardial repolarisation assessed by the scalar electrocardiogram (lead I) was unchanged; local activation time increased by $5 \mathrm{~ms}$ in the lower tracings. Pacing at a faster rate (CL, $430 \mathrm{~ms})$ produced angina and electrocardiographic changes.

ing clinical ischaemia by a mean of $28 \mathrm{~ms}(10.6 \%$ of control values) when compared with the right ventricular non-ischaemic recordings at identical paced rates. This shortening of repolarisation from the ischaemic zone was documented at lower rates than those required to induce angina (Fig. 6) and preceded clinical evidence of ischaemia by up to five minutes. The duration of the local repolarisation shortened to a greater extent in the two patients who developed ischaemia with electrocardiographic ST segment depression and $\mathrm{T}$ inversion compared with those patients with ischaemia and ST depression only (Table). Throughout the pacing study the electrocardiogram showed no significant changes in the duration of overall myocardial repolarisation (Fig. 6), showing only the expected rate related decrease in the QT interval documented in normal subjects. The local activation time derived from the paced endocardial evoked response during clinical ischaemia was 38.6 (SD) $\pm 8.4 \mathrm{~ms}$ in the control non-ischaemic zone and $42.4 \pm 8.42 \mathrm{~ms}$ in the ischaemic zone $(\mathrm{p}<0.001)$ (Table). In two patients, however, fragmented deflections caused by non-homogeneous activation were recorded from the ischaemic area (Fig. 7), and these deflections made the accurate quantification of local activation time difficult. Exclusion of the data from those two patients did not alter the significance of the delay in activation.

The simultaneous paced monophasic action potentials from the ischaemic zone also showed a decrease in amplitude and in the duration of the repolarisation

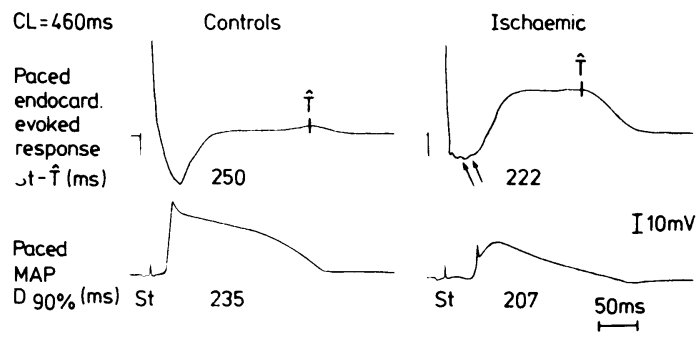

Fig. 7 Effect of ischaemia on the paced endocardial evoked response and on the simultaneous paced monophasic action potentials (MAP). Recordings obtained from the catheters positioned in the non-ischaemic (control) and ischaemic zones at paced cycle length $=460 \mathrm{~ms}$ (case 4$)$. The repolarisation time as measured on the paced endocardial evoked response decreased by $28 \mathrm{~ms}$ and local activation became fragmented and delayed (arrows). In the paced monophasic action potential tracings there was a parallel (28 ms) shortening of the repolarisation time $\left(D_{90 \%}\right)$ and a decrease in monophasic action potential amplitude. Local conduction (St - MAP upstroke) was delayed by $16 \mathrm{~ms}$.

in excess of the expected rate dependent changes (Fig. 8) while monophasic action potentials from the nonischaemic zone showed no changes during regional ischaemia. The $90 \%$ monophasic action potential repolarisation time from the non-ischaemic zone measured at angina averaged $255.5(\mathrm{SD}) \pm 14 \mathrm{~ms}$; the

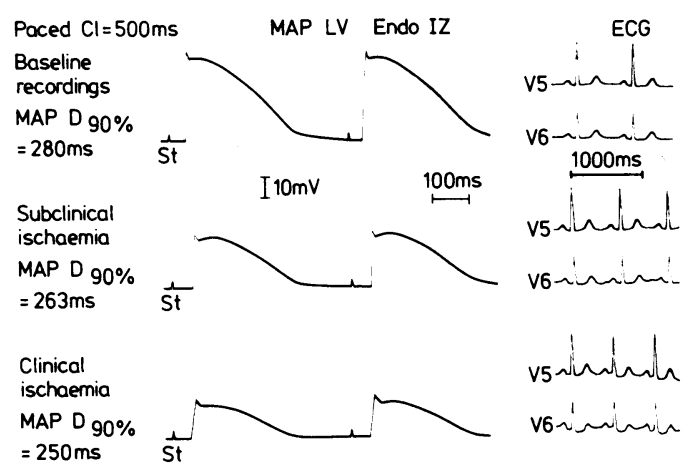

Fig. 8 Continuous recordings of the left ventricular endocardial monophasic action potential from the ischaemic zone (Endo IZ) during pacing at the threshold rate for angina until the onset of clinical ischaemia (case 10). The baseline tracings correspond to the start of the pacing run. The second tracing was recorded three minutes later, before the onset of angina and electrocardiographic abnormalities and shows the characteristic decreases in monophasic action potential amplitude and repolarisation time ( $D_{90 \%}$ ) of subendocardial ischaemia. These changes were more manifest in the third tracing when both clinical and electrocardiographic evidence of ischaemia became evident. The top unpaced electrocardiograms (leads V5 and V6) were obtained before the pacing run; the other electrocardiograms were recorded within seconds of the corresponding monophasic action potential recordings. 
simultaneous monophasic action potential from the ischaemic zone averaged $229.2 \pm 12.8 \mathrm{~ms}(p<0.001)$ during ischaemia (Table). This monophasic action potential shortening paralleled the shortening of the simultaneous paced endocardial evoked response (Table and Fig. 7). Analysis of the tracings obtained from the ischaemic zone also showed that the shortening of the monophasic action potential repolarisation time and amplitude were overt at lower paced rates than those required tu produce clinical or electrocardiographic evidence of ischaemia.

The local conduction time in the ischaemic zone was prolonged at the end point of the study from $25.9 \pm 4.85$ in the non-ischaemic zone to $34 \pm 8 \mathrm{~ms}$ in the ischaemic zone (Table). Because the ischaemic zone was activated with delay, repolarisation of the ischaemic area did not always terminate much earlier than the repolarisation of the non-ischaemic areas, even though the latter had longer refractory periods (Fig. 9).

After recovery from the initial study continuous paced endocardial evoked response and monophasic action potential recordings were obtained in four patients while pacing at the predetermined threshold rate for angina; in these fixed rate studies, significant changes in repolarisation time preceded clinical evidence of ischaemia by a mean of two-and-a-half minutes (Fig. 8).

After cessation of angina and ischaemia, the ischaemic changes in repolarisation time in the left ventricle reversed rapidly, invariably within $30 \mathrm{sec}-$ onds.

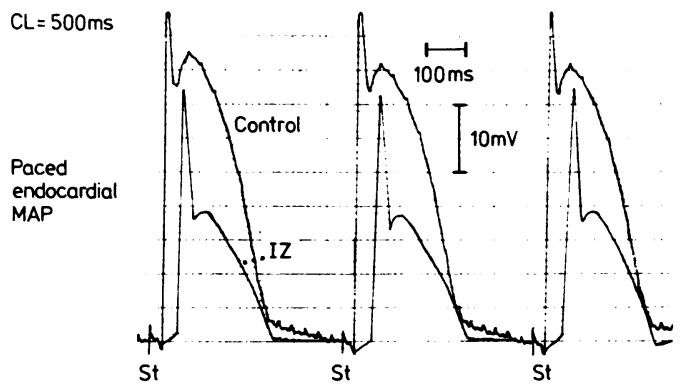

Fig. 9 Superimposed paced endocardial monophasic action potential recordings from the non-ischaemic (control) zone and from the ischaemic zone (IZ) during angina and regional ischaemia (case 9). The "control" monophasic action potential recordings are from the catheter positioned in the inferobasal portion of the right ventricle and have a duration of $268 \mathrm{~ms}$. The monophasic action potential from the ischaemic zone have reduced amplitude and duration $\left(D_{90 \%}=230 \mathrm{~ms}\right)$. Conduction time (St - MAP upstroke) is delayed in the ischaemic area by 25 ms.

\section{Discussion}

The localised ionic and electrical changes that occur during the early phases of regional ischaemia lead to a decrease in the resting membrane potential, shortening of action potential duration, and delay in local conduction. ${ }^{25}$ These changes influence the development of the ventricular arrhythmias of the early phase of ischaemia ${ }^{511} 12$; abnormally enhanced automaticity and delayed after-depolarisation may also play a role in this context.

There is need for an electrophysiological technique to detect and monitor the early electrical changes that could be applicable in the clinical setting. Because the initial ischaemic injury occurs first in the subendocardium, ${ }^{1314}$ intracavitary recordings should provide sensitive indices of regional ischaemia. It should be emphasised, however, that all extracellular electrode recordings reflect the average effects of many cells with disparate repolarisation and refractory times and are thus prone to some inadequacies, and that the ability to localise a catheter in the left ventricle is limited to a fairly large area. ${ }^{15}$ Recent work on the slow adaptation phase of repolarisation time to rapid changes in cycle length ${ }^{16} 17$ suggests that perhaps longer pacing periods at each of the different cycle lengths might be required for greater accuracy.

The present investigation was undertaken to determine if clinically applicable intracardiac electrodes could reliably detect and monitor the early electrophysiological changes of ischaemia in man. The paced endocardial evoked response system has the advantage of clinical simplicity requiring only a conventional pacing electrode lead. As the same lead is used for pacing and sensing, it is possible to record the pacing induced depolarisation and the evoked $\mathrm{T}$ wave which represents the dominantly local repolarisation which follows from the same site. ${ }^{9}$ Both QRS and $T$ wave durations are shorter than those observed in the simultaneous electrocardiogram (Fig. 2) as the evoked response sensed by the pacing electrode is dominated by electrical events local to the depolarising electrode. 9 Monophasic action potentials have been shown to correlate well with the shape and duration simultaneous transmembrane potentials at the recording site. ${ }^{18}$ Though pacing evoked endocardial response and monophasic action potential duration are similar in both ventricles and normally represent a measurement of the local refractory period of the myocardium, this is not necessarily true for ischaemic tissue, where post-repolarisation refractoriness may cause a disparity between action potential duration and refractoriness. ${ }^{5}$

Measurements of the duration of the paced endocardial evoked response and monophasic action potentials at matched heart rates during and after the 
stress induced deficiency in myocardial blood supply eliminated rate dependent differences in the recordings and allowed the direct comparison of changes in local repolarisation and activation time between ischaemic and non-ischaemic zones.

The abnormal shortening of the local repolarisation time in the pacing evoked endocardial response from the ischaemic zone (Fig. 5 and 6) was closely followed by divergent decreases in duration of the simultaneous paced monophasic action potentials from controls (Table and Fig. 7). The average rate corrected shortening of the local repolarisation time in the ischaemic area was $10.4 \%$ ( $27 \mathrm{~ms})$. A decrease of more than $5 \%$ ( $95 \%$ confidence limits) of the repolarisation as evaluated by either method should thus enable the diagnosis of subclinical or early ischaemia (Fig. 5, 6, and 8). This decrease in the repolarisation time is probably partially related to the severity of the ischaemia ${ }^{19}$ and was much more pronounced in the two patients in whom $T$ wave inversion documented electrocardiographically during angina.

The intracavitary recordings appear to be very sensitive in detecting ischaemia. Abnormal shortening of the paced endocardial evoked response and changes in amplitude and duration in the monophasic action potential tracings from the ischaemic left ventricular zone preceded the symptoms and electrocardiographic abnormalities. Thus, pacing evoked endocardial response shortening occurred at rates up to 20 beats/min lower than those required to induce clinical or electrocardiographic evidence of ischaemia, and preceded the latter by up to five minutes (Fig. 6). Changes in monophasic action potential duration and amplitude also preceded clinical ischaemia, even during pacing at the threshold rate (Fig. 8).

A progressive delay in the local activation time during angina (average $4 \mathrm{~ms}$ ) was documented by the paced endocardial evoked response from the ischaemic zone. The measurement of activation time during angina by this method is, however, prone to inaccuracies because of the fragmentation of the myocardial activation which is sometimes seen (Fig. 7). The monophasic action potential tracings from the ischaemic area recorded a mean $8 \mathrm{~ms}$ delay in the local conduction time (Table). Non-ischaemic areas showed no changes in the pattern of activation and repolarisation (Fig. 9) as evaluated by these intracavitary electrodes. These ischaemic changes in local activation, conduction, and repolarisation reversed rapidly; recovery of the ability of cells to generate action potentials with amplitude and duration equivalent to the basic control measurements occurred always within 30 seconds of the administration of intravenous nitrates and the cessation of angina, and also preceded the electrocardiographic regression of myocardial ischaemia.
These studies have thus shown that the ischaemic zone is activated with delay and that disparate repolarisation times exist within the ischaemic left ventricle (Fig. 9). The disparity in activation and repolarisation times documented by the pacing evoked endocardial response and monophasic action potential tracings from non-ischaemic and ischaemic myocardial zones is compatible with the requirements for the appearance of re-entry arrhythmias. ${ }^{1120}$ Fractionated electrograms similar to those recorded in two cases by the paced endocardial evoked response (Fig. 7) have been previously noted in epicardial electrograms during ischaemia. ${ }^{1121}$ This irregularity in local activation is probably the result of the non-uniform effects of ischaemia on the activation of the myocardium.

Intracavitary recordings may thus provide earlier and more sensitive detection of regional subendocardial ischaemia during cardiac catheterisation or coronary artery surgery. Our initial experiments in dogs ${ }^{6}$ suggest that the study of the patterns of activation and response could permit the assessment of pharmacological, metabolic, or haemodynamic interventions on the early electrical changes of ischaemia and on the preservation of the ischaemic myocardium. They may bridge the gap between in vitro studies and the electrophysiological studies performed upon the intact heart.

\section{References}

1 Bache RJ, McHale PA, Greenfield JC Jr. Transmural myocardial perfusion during restricted coronary inflow in the awake dog. Am f Physiol 1977; 232:645-51.

2 Lazzara R, El-Sherif N, Scherlag BJ. Early and late effects of coronary artery occlusion on canine Purkinje fibers. Circ Res 1974; 35: 391-9.

3 Battler A, Froelicher VF, Gallagher KP, Kemper WS, Ross J Jr. Dissociation between regional myocardial dysfunction and ECG changes during ischemia in the conscious dog. Circulation 1980; 62: 735-44.

4 Wegria R, Segers M, Keating RP, Ward HP. Relationship between the reduction in coronary flow and the appearance of electrocardiographic changes. Am Heart $\mathcal{F}$ 1949; 38: 90-6.

5 Janse MJ, Kléber AG. Electrophysiological changes and ventricular arrhythmias in the early phase of regional myocardial ischemia. Circ Res 1981; 49: 1069-81.

6 Donaldson RM, Taggart P, Nashat F, Abed J, Rickards AF, Noble D. Study of the electrophysiological effects of early or subendocardial ischaemia using intracavitary electrodes. Clin Sci (in press).

7 Selzer A, Cohn K, Goldschlager N. On the interpretation of the exercise test. Circulation 1978; 58: 193-5.

8 Pohost GM, Zir LM, Moore RH, McKusick KA, Guiney TE, Beller GA. Differentiation of transiently ischemic from infarcted myocardium by serial imaging after a single dose of thallium-201. Circulation 1976; 55: 294-302. 
9 Donaldson RM, Rickards AF. Evaluation of druginduced changes in myocardial repolarisation using the paced evoked response. $\mathrm{Br}$ Heart $\mathcal{F}$ 1982; 48: 381-7.

10 Olsson B, Varnauskas E, Korsgren M. Further improved method for measuring monophasic action potentials of the intact human heart. $f$ Electrocardiol 1971; 4: 19-23.

11 Boineau JP, Cox JL. Slow ventricular activation in acute myocardial infarction. A source of reentrant premature ventricular contractions. Circulation 1973; 48: 702-13.

12 Lazzara R, El-Sherif N, Hope RR, Scherlag BJ. Ventricular arrhythmias and electrophysiological consequences of myocardial ischemia and infarction. Circ Res 1978; 42: 740-9.

13 Marcus ML, Kerber RE, Ehrhardt J, Abboud FM. Three dimensional geometry of acute ischemic myocardium. Circulation 1975; 52: 254-63.

14 Rivas F, Cobb FR, Bache RJ, Greenfield JC Jr. Relationship between blood flow to ischemic regions and extent of myocardial infarction. Circ Res 1976; 38: 439-47.

15 Waxman HL, Josephson ME. Ventricular activation during ventricular endocardial pacing: I. Electrocardiographic patterns related to the site of pacing. Am $\mathcal{Y}$ Cardiol 1982; 50: 1-10.

16 Franz MR, Platia EV, Schaefer J, Reid PR. Fast and slow adaptation of human monophasic action potentials to abrupt changes in heart rate [Abstract]. Am $\mathcal{f}$ Cardiol 1982; 49: 970.

17 Arnold L, Page J, Attwell D, Cannell M, Eisner DA. The dependence on heart rate of the human ventricular action potential duration. Cardiovasc Res 1982; 16: 54751.

18 Hoffman BF, Cranefield PF, Lepeschkin E, Surawicz R, Herrlich HC. Comparison of cardiac monophasic action potentials recorded by intracellular and suction electrodes. Am F Physiol 1959; 196: 1297-302.

19 Noble D. The interpretation of the electrocardiogram. In: The initiation of the heart beat. Oxford: Clarendon Press, 1979: 132-49.

20 Waldo AL, Kaiser GA. A study of ventricular arrhythmias associated with acute myocardial infarction in the canine heart. Circulation 1973; 47: 1222-8.

21 Elharrar V, Gaum WE, Zipes DP. Effect of drugs on conduction delay and incidence of ventricular arrhythmias induced by acute coronary occlusion in dogs. $A m \mathcal{F}$ Cardiol 1977; 39: 544-9.

Requests for reprints to Dr R M Donaldson, National Heart Hospital, Westmoreland Street, London W1M 8BA. 